\title{
CURRENT ASPECTS IN THE RECOVERY OF ORAL CAVITY FUNCTIONS DURING MIXED DENTITION
}

\author{
Andreea D. IORDAN DUMITRU1 ${ }^{1}$, Horia LAZARESCU², Andrei KOZMA ${ }^{3 * \otimes}$, \\ Agnes K. LACKNER ${ }^{4}$, Doriana AGOP-FORNA ${ }^{5}$
}

${ }^{1}$ „Titu Maiorescu“ University, Faculty of Dental Medicine, Bucharest, Romania

${ }^{2}$ National Institute of Recovery, Physical medicine and Balneoclimatology, Bucharest, Romania

3 "Alessandrescu - Rusescu“ National Institute for Mother and Child Health, Bucharest, Romania

${ }^{4}$ Medical University Vienna, University Dental Clinic, Department of Paediatric Dentistry, Vienna, Austria

${ }^{5}$ Dental Medicine Faculty, "Grigore T. Popa" University of Medicine and Pharmacy, Iasi, Romania

Received 22 March 2019, Accepted 03 May 2019

https://doi.org/10.31688/ABMU.2019.54.2.10

\section{Abstract}

The objective of the study was to analyze a phenomenon that is more and more common in dental practice, i.e. the simultaneous presence on the arch of both the temporary tooth and the successor tooth.

Material and method. The study has been conducted for over a year $(1.01 .2018-31.12 .2018)$ by the authors practicing in Romania. From the total number of patients, we selected and studied those who had in the oral cavity both their temporary teeth and their successor teeth. In addition to their recording in the oral cavity, where appropriate, the temporary teeth extraction was used to place the definitive ones so that the functions of the dental-maxillary apparatus would not be altered.

Results. 272 children with different pathologies at the oral cavity level were evaluated, of whom 102 children $(37.5 \%)$ presented both temporary and definitive successor teeth. There were no significant differences between the two sexes. In the majority of cases, the temporary teeth and the definitive teeth were not in the same plane so that, on the arches line, the

\section{RÉsumé}

Aspects actuels de la récupération des fonctions de la cavité orale pendant la dentition mixte

L'objectif de l'étude a été d'analyser un phénomène de plus en plus courant dans la pratique dentaire, à savoir la présence simultanée sur l'arcade dentaire, de la dentition temporaire et de la dentition suivante.

Matériel et méthodes. L'étude a été conduite par les auteurs sur une période d'une année (1.01.2018-31.12.2018), en Roumanie. A partir du nombre total de patients, on a envisagé de différencier et d'étudier ceux qui présentaient dans la cavité buccale à la fois les dents temporaires et les dents successeurs. En plus de leur enregistrement dans la cavité buccale, le cas échéant, l'extraction temporaire des dents a été utilisée pour placer les dents définitives de manière à ne pas altérer les fonctions de l'appareil dento-maxillaire.

Résultats. 272 enfants présentant différentes pathologies de la cavité buccale ont été examinés, dont 102 (37,5\%) ont présenté des dents successives temporaires 
temporary ones and the permanent ones had an ectopic position; the temporary teeth had unreabsorbed roots and the final teeth had a defective position.

Conclusions. Presence on the arches of both the definitive teeth and the temporal teeth leads to malocclusions that, if not corrected, the entire oral cavity will be damaged. If teeth with malposition do not return to their normal place on the arch, the patient will be directed to the orthodontic specialist.

Keywords: temporary teeth, definitive teeth, recovery, simultaneous, eruption.

\section{INTRODUCTION}

Although researchers agree that tooth eruption is a complex process, there is little agreement on the identity of the mechanism that controls eruption. ${ }^{1}$ According to the theories of dental growth displacement, teeth are pushed upward into the mouth by the growth of the teeth's roots in opposite direction. ${ }^{2}$ Regarding this theory, the continued bone formation determines this growth and eruption, the tooth is pushed upward by the growth of the bone around the tooth. The most widely held current theory is that while several forces might be involved in eruption, the periodontal ligament provides the main impetus for the process.

Theorists hypothesize that the periodontal ligament promotes eruption through the shrinking and cross-linking of their collagen fibers and the contraction of their fibroblasts. ${ }^{3}$ This new theory proposes firstly that areas of tension and compression are generated in the soft tissues surrounding unerupted teeth by the distribution of bite forces through the jaws. These patterns of tension and compression, are further proposed to result in patterns of bone resorption and deposition that lift the tooth into the mouth. ${ }^{4}$ This theory is based on Wolff's Law, which is the longest established idea that bone changes shape in accordance with the forces applied. ${ }^{5}$ Significantly, a recent finite element analysis study, analyzing the distribution of force through the jaw of an 8-year-old child, observed overall compression in the soft tissues above, and tension in the soft tissues below, unerupted teeth. ${ }^{4}$. After the last primary tooth is shed or exfoliates out of the mouth, the teeth are in the permanent dentition stage. Each et définitives dans la cavité buccale. Il n'y a pas de différences significatives entre les deux sexes. Dans la majorité des cas, les dents temporaires et les dents définitives n'étaient pas dans le même plan, de sorte que sur la ligne de l'arcade se trouvaient les dents temporaires et que les dents définitives avaient une position ectopique; les dents temporaires avaient une racine non résolue et les dernières dents étaient en inocclusion.

Conclusions: La présence sur l'arcade de la dent définitive et de la dent temporaire produit des malocclusions qui, si elles ne sont pas corrigées, affecteront toute la cavité buccale. Si les dents mal positionnées ne retrouvent pas leur place normale dans l'arcade, le patient sera dirigé vers un orthodontiste.

Mots-clés: dents temporaires, dents définitives, récupération, simultané, éruption.

patient should be assigned a dentition period to allow for effective dental treatment. ${ }^{6}$

The period of mixed teeth is marked by many changes, both functional and aesthetic. These changes can contribute to installing disruptions at masticatory, phonetic and aesthetic levels. If any primary teeth are shed or lost before permanent teeth are ready to replace them, some posterior teeth may drift forward and cause space to be lost in the mouth. ${ }^{7}$ This may cause crowding and/or misplacement once the permanent teeth erupt, which is usually referred to as malocclusion. Malocclusion is a common finding, ${ }^{8,9}$ although it is not usually serious enough to require treatment. Abnormalities in tooth eruption (timing and sequence) is often caused by genetics and may result in malocclusion. In severe cases, such as in Down syndrome, the eruption may be delayed by several years and some teeth may never erupt $\mathrm{t}^{10.13}$.

These problems occurring during mixed dentition require specific treatments for the recovery of oral cavity functions. If the case may be, it is necessary to extract temporary teeth that do not exfoliate alone or even to prevent a non-functional occlusion it is recommended to use orthodontic appliances for proper restoring of the occlusion as well as of the phonetic and aesthetic aspect.

THE OBJective OF THE STUDY was to analyze this phenomenon that is more and more common in dental practice, i.e. the simultaneous presence on the arch of both the temporary tooth and the successor tooth.

\section{Material AND MEthods}

The study was conducted over a year (1.01.2018. 31.12.2018) from authors practice in Romania, where 


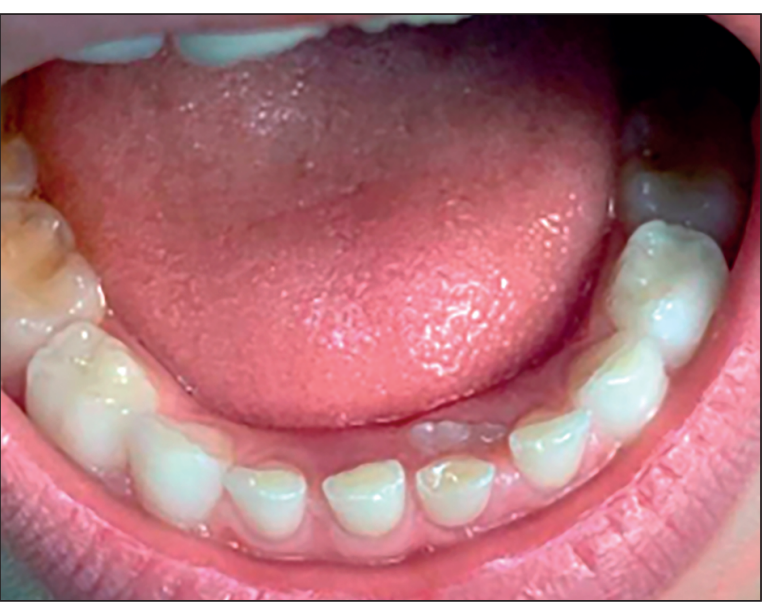

Figure 1a: Patient, female, 5 years and 7 months old oral appearance of the lower arcade

it was intended, from the number of patients studied, to differentiate and study those who had both temporary and succession teeth at the oral cavity level. In addition to their recording in the oral cavity, where appropriate, the temporary teeth were extracted to make room for the definitive teeth so that the functions of the dental-maxillary apparatus were not altered, as well as the recommendation of an orthodontic consultation, where appropriate.

\section{Results}

The total number of patients for this study was 272. Of these, only those who presented the deciduous tooth and the successor on the arcade were selected. This category represented $37.2 \%$, respectively 102 patients. The reason for the presentation in the dental office was in most cases (83\%): disturbance of the oral cavity functions, and patients demanding the functional and aesthetic solution of this inconvenience.

The gender distribution was evenly divided, with no important significance as deviance from normal dental status.

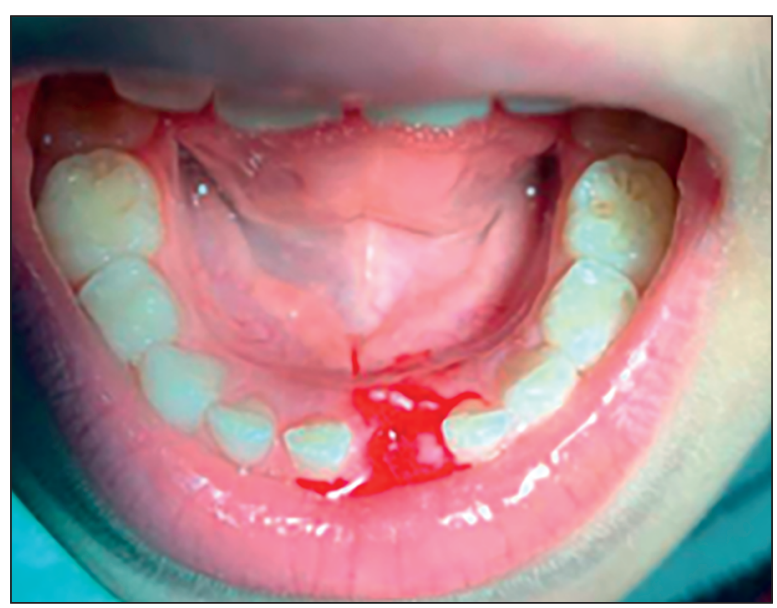

Figure 1b: Patient, female, 5 years and 7 months old intraoral appearance after the extraction of 71

The area most affected by this phenomenon, studied by us, was the inferior incisive area with 63 patients $(61.76 \%)$, followed by the area between the temporary molars with 27 patients $(26.47 \%)$ and the incisive upper level with 12 patients, respectively $11.77 \%$.

\section{Case 1}

Patient R.N., 5 years and 7 months old, female, presented to the dentist accusing difficulties in mastication and phonation. At the intraoral consultation, after performing the dental status, the presence of 71 lingual of 31 (Fig. 1a) is observed. The extraction of 71 with some mobility is decided, in order to make room on the arch, in the right place, of definitive tooth 31, and to restore its casting, the aesthetic appearance and last but not least the occlusion (Fig. 1b).

\section{Case 2}

Patient T.A., 9 years and 2 months old, male, presented to the dentist with pain in the area of bilateral temporary molars (Fig 2a, b). It is also noted that there is an aesthetic and masticatory disorder. Due
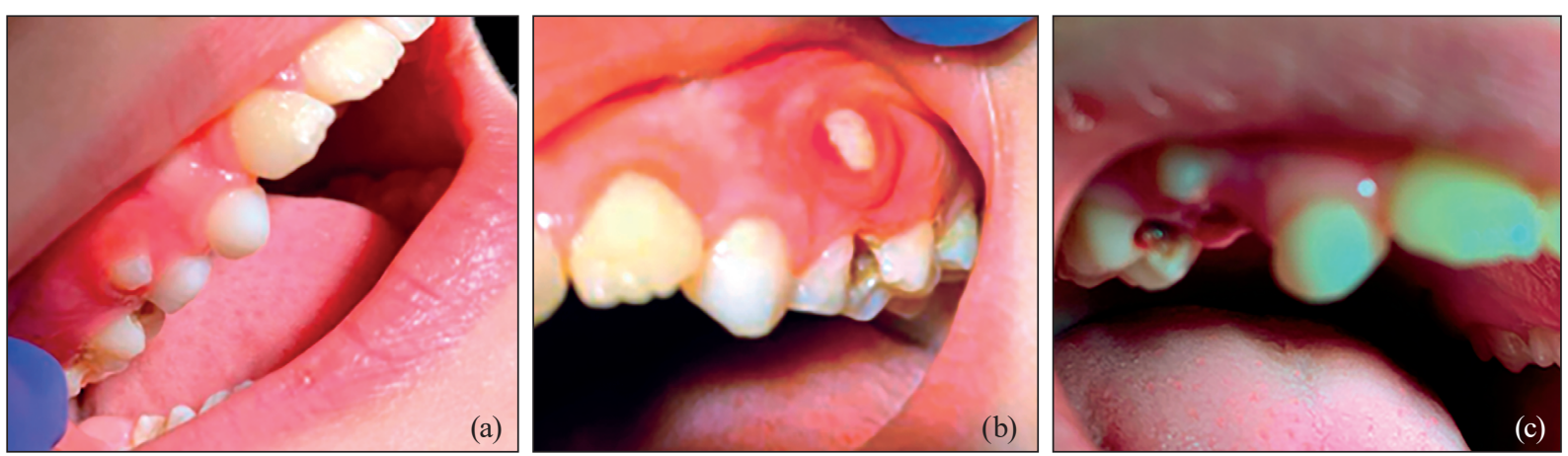

Figure 2: Patient., male, 9 years and 2 months old - Intraoral appearance of right hemiarcade

(a) of left hemiarcade (b) and after the extraction of 5.4 (c) 

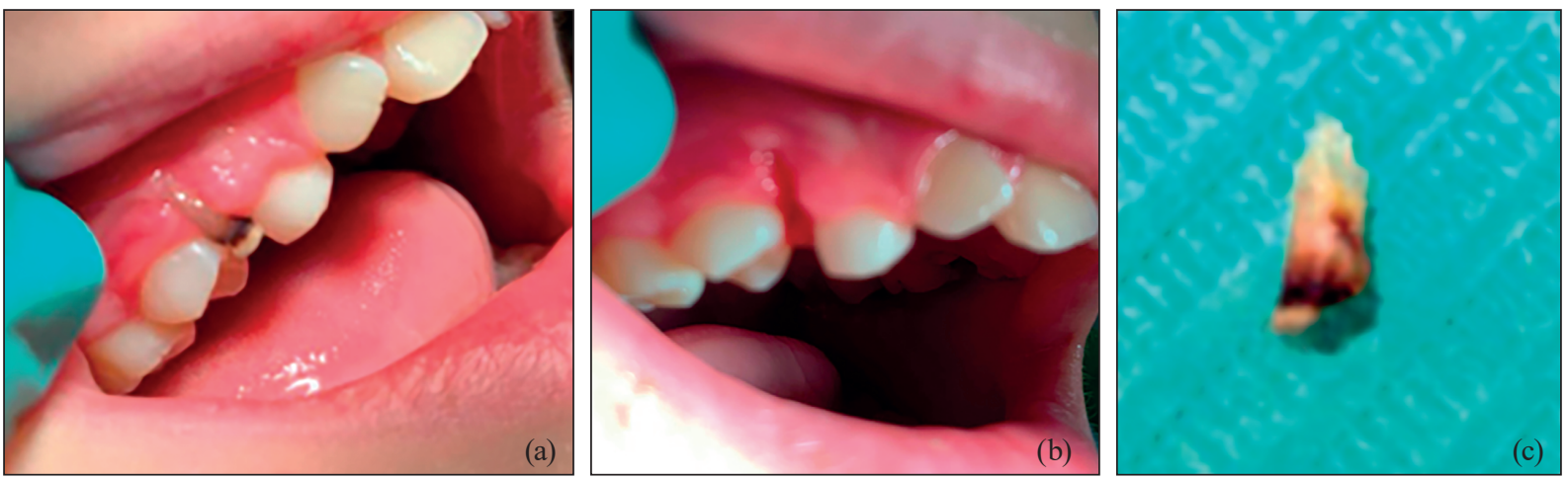

Figure 3: Patient, male, 8 years and 7 months old -

oral appearance (a), after extraction of 5.4 (b) and aspect of the radical residue of 54

to the pain in this area, the patient cannot perform a proper hygiene, the area of the eruption of the definitive teeth endowing areas of the irritated gingival mucosa following poor hygiene.

It is recommended to extract the temporary teeth from both quadrants (5 and 6) to leave the definitive premolars 14 and 24 respectively (Fig. 2c). If the premolars do not return to their normal place on the arch, the patient will be directed to an orthodontist.

\section{Case 3}

Patient R.A., male, 8 years and 7 months old, presented to the dentist with pain in the first quadrant, and after the check-up, the presence of a radicular rest between 53 and 14 is observed. In addition to the physiological disorder there is also a malocclusion due to the dento-alveolar incongruence that pushes vestibularly on 12 (Fig. 3a). It is recommended to urgently extract the radical root of 54 and a visit to the orthodontist is recommended, in order to restore as soon as possible, the correct and aesthetic function of the oral cavity. After extraction (Fig. 3b) one can observe the space occupied by the rest of 54 and the length of its root, its resorption being partial (Fig. 3c).

\section{Case 4}

Patient H.D., female, 7 years and 3 months old, presented to the dentist with problems of swallowing and phonation. As a result of the consult, it is observed at the level of the left hemiarch, in a palatine position, 21 which erupts (Fig. 4), on the line of the arcade where there is 61 . From the anamnesis it appears that the patient did not suffer a trauma at this level, 21 is coming out in this position without the action of other external factors. The extraction of 61 and the orthodontic specialist consult are recommended. The patient is very anxious, so he delays the interventions that would have helped to resolve the problems.

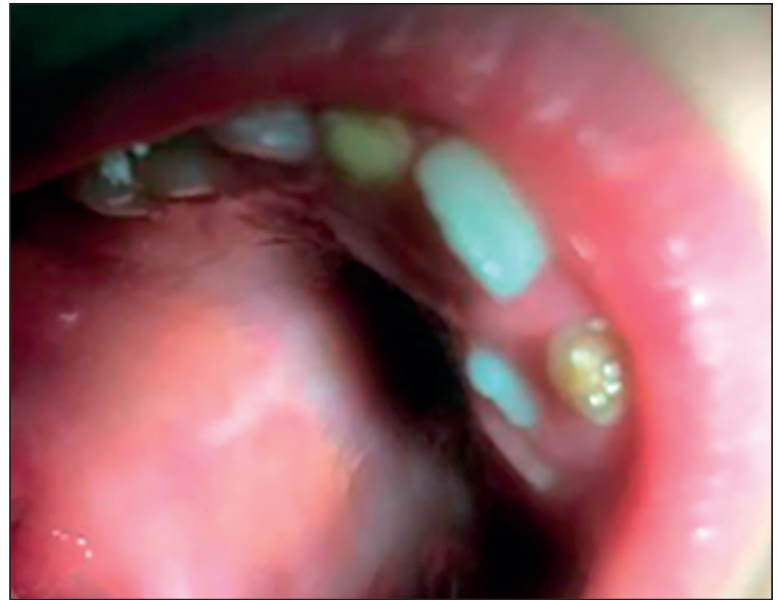

Figure 4: Patient, female, 7 years and 3 months old - oral appearance

\section{Discussion}

The gender distribution was evenly divided, with no significant difference.

The areas with the greatest damage were: upper premolars, followed by inferior incisors and upper incisors.

In most cases, a local anesthesia had to be performed, because the deciduous teeth to be removed had reduced mobility. After extraction, roots that were only partially reabsorbed or not reabsorbed could be observed. This phenomenon has not yet been fully elucidated. There are many theories regarding it, similar to those of the eruption.

After the extraction of the deciduous tooth in most cases, it was recommended that the patient should visit an orthodontist for the total recovery of the altered functions.

There have also been situations in which by simply pushing the succession tooth with the tongue after the extraction of the deciduous tooth, the final tooth reached its place on the arch. 


\section{Conclusions}

In most cases the temporary teeth and the definitive teeth were not in the same plane so that on the arch line there were both the temporary and the definitive teeth in an ectopic position.

Presence on the arch of both the definitive tooth and the temporal tooth produces malocclusions which, if not corrected, the entire oral cavity will suffer. If teeth with malposition do not return to their normal place on the arch, the patient will be directed to an orthodontist.

\section{Compliance with ethics requirements:}

„The authors declare no conflict of interest regarding this article."

"The authors declare that all the procedures and experiments of this study respect the ethical standards in the Helsinki Declaration of 1975, as revised in 2008, as well as the national law. The informed consent was obtained from the patients included in the study."

"No funding for this study."

„All authors contributed equally to the study and take responsibility for the integrity of the data and the accuracy of the data analysis."

\section{References}

1. Riolo ML, Avery JK. Essentials for orthodontic practice. 1st edition, Grand Haven, MI, 2003.
2. Marks SC, Jr., Schroeder HE. Tooth eruption: theories and facts. The Anatomical Record. 1996;245(2):374-393.

3. Wilton MK. Craniofacial growth and development: an appraisal. Journal of the American Dental Association 1973;87(5):1037-1043.

4. Sarrafpour B, Swain M, Li Q, Zoellner H. Tooth eruption results from bone remodeling driven by bite forces sensed by soft tissue dental follicles: a finite element analysis. PLoS One. 2013;8(3):e58803.

5. Frost HM. A 2003 update of bone physiology and Wolff's Law for clinicians. Angle Orthod. 2004;74(1):3-15.

6. Bath-Balogh M, Fehrenbach M. llustrated dental embryology, histology, and anatomy. Elsevier, 2011, page 191-192.

7. Vardimon AD, Matsaev E, Lieberman M, Brosh T. Tightness of dental contact points in spaced and non-spaced permanent dentitions. European Journal of Orthodontics 2001; 23(3):305-14.

8. Thilander B, Pena L, Infante C, Parada SS, de Mayorga C. Prevalence of malocclusion and orthodontic treatment need in children and adolescents in Bogota, Colombia. An epidemiological study related to different stages of dental development. European Journal of Orthodontics. 2001;23(2):153-67.

9. Borzabadi-Farahani A, Borzabadi-Farahani A, Eslamipour F. Malocclusion and occlusal traits in an urban Iranian population. An epidemiological study of 11- to 14-year-old children. European Journal of Orthodontics. 2009;31(5): 477-84.

10. Wysocki JPS, Lewis RE, George P. Contemporary oral and maxillofacial pathology (2nd ed.). St. Louis: Mosby, 2002, pp. 39-40.

11. Cawson RA, Odell EW. Cawson's essentials of oral pathology and oral medicine (8th ed.). Edinburgh: Churchill Livingstone. 2012, pp. 419-421.

12. McDonald RE, Avery DR, Jeffrey A. Dentistry for the child and adolescent (8. ed.). St. Louis, Mo: Mosby. 2004. pp. 164-168, 190-194, 474.

13. Regezi JA, Sciubba JJ, Jordan RCK. Oral pathology: clinical pathologic correlations (5th ed.). St Louis, Missouri: Saunders Elsevier. 2008, pp. 353-354. 